\title{
Identification of small molecules inhibitors of GCN5 histone acetyltransferase activity
}

\section{Antonello Mai, ${ }^{* \S}$ Dante Rotili, ${ }^{\S}$ Prisca Ornaghi, ${ }^{\#}$ Federica Tosi, ${ }^{\#}$ Caterina Vicidomini, Gianluca Sbardella, ${ }^{\ddagger}$ Angela Nebbioso, ${ }^{\wedge}$ Lucia Altucci, ${ }^{\wedge} \circ$ and Patrizia Filetici*, ${ }^{*}$}

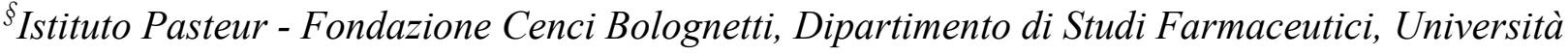
degli Studi di Roma "La Sapienza”, P.le A. Moro 5, 00185 Roma, Italy "Dipartimento di Genetica e Biologia Molecolare, Università degli Studi di Roma “La Sapienza”, P.le A. Moro 5, 00185 Roma, Italy

${ }^{*}$ Dipartimento di Scienze Farmaceutiche, Università degli Studi di Salerno, via Ponte Don Melillo, 84084 Fisciano (SA), Italy

^Dipartimento di Patologia Generale, Seconda Università degli Studi di Napoli, vico L. De Crecchio 7, 80138 Napoli, Italy

${ }^{\circ}$ Centro di Oncogenomica AIRC, CEINGE Biotecnologia avanzata, Napoli

"Istituto di Biologia e Patologia Molecolari CNR, Dip. Genetica e Biologia Molecolare, Università degli Studi di Roma "La Sapienza”, P.le A. Moro 5, 00185 Roma, Italy

E-mail: antonello.mai@uniroma1.it, patrizia.filetici@uniroma1.it

\begin{abstract}
Starting from a yeast phenotypic screening performed on 21 chemically different substances we described the discovery of two small molecules as GCN5 inhibitors. The 2-methyl-3carbethoxyquinoline 9 and its 2-desmethyl analogue 18 were able to significantly reduce the yeast cell growth, thus miming the effect of GCN5 deletion mutant. Tested to evaluate their effect on GCN5-dependent transcription of the HIS3 gene, 9 and $\mathbf{1 8}$ showed high inhibitory activity of gene transcription, more evident in activated conditions. Compound $\mathbf{9}$ was also able to reduce the acetylation levels of $\mathrm{H} 3$ and, to a lesser extent, $\mathrm{H} 4$ in yeast at $0.6 \mathrm{mM}$. In human leukemia U937 cells, at $1 \mathrm{mM}$ concentration 9 showed 27\% apoptosis induction, while 18 had just a little effect in the same conditions. Further studies on $\mathbf{9}$ and $\mathbf{1 8}$ will be performed to deepen their effects on GCN5-related phenomena.
\end{abstract}

Keywords: GCN5, HAT, acetylation, chromatin remodelling, yeast 


\section{Introduction}

The reversible process of histone acetylation occurring at the $\varepsilon$-amino group of lysine residues in the $N$-terminal tails of core histones mediates conformational changes in nucleosomes. Two classes of enzymes are involved in such process: histone acetyltransferases (HATs) and histone deacetylases (HDACs), which catalyze the addition to and removal, respectively, of acetyl units to histones. These modifications affect the accessibility of transcription factors to DNA and regulate gene expression, ${ }^{1-5}$ histones hyperacetylated or hypoacetylated being associated with the transcriptionally active euchromatin or the gene silencing eterochromatin, respectively. ${ }^{6-9}$

The first nuclear HAT to be discovered, general control of nuclear-5 (GCN5), and its paralog, p300/CBP accessory factor (PCAF), are conserved in organisms from yeast to humans. ${ }^{10-12}$ Similarly to HDACs, GCN5/PCAF are typically found in large multiprotein complexes in cells such as SAGA and ADA, nevertheless unlike HDACs they exhibit robust catalytic activity as purified proteins, with high selectivity for $\mathrm{H} 3 \mathrm{~K} 14 .{ }^{13-16}$

The anticancer effects of HDAC inhibitors (HDACi) are well known, and a number of them are in clinical trials, ${ }^{17,18}$ while the chemotherapeutic potential of HAT targets has been less validated. Missense and deletion mutations in the p300 gene have been found in colorectal, gastric, and epithelial cancers, and the loss of heterozygosity of p300 gene has been related to glioblastoma. ${ }^{19,20}$ p300 and PCAF have been reported to play an important role in MyoD dependent cell cycle arrest, ${ }^{21}$ and dysregulation of GCN5/PCAF in genetic diseases and cancer has led to the supposition that selective inhibitors of these HATs may have therapeutic applications. $^{22,23}$

To date, a small number of HAT inhibitors has been reported. Among them, the bi-substrate analogues Lys-CoA and H3-CoA-20 are selective for p300 and PCAF, respectively. ${ }^{24}$ Some natural products such as anacardic acid, ${ }^{25}$ garcinol, ${ }^{26}$ and curcumin $^{27}$ have been reported as potent p300 and PCAF inhibitors, and recently the $\gamma$-butyrolactone MB-3 and a series of isothiazolones have been disclosed as inhibitors of both p300 and PCAF HAT activities ${ }^{28,} 29$ (Figure 1). 

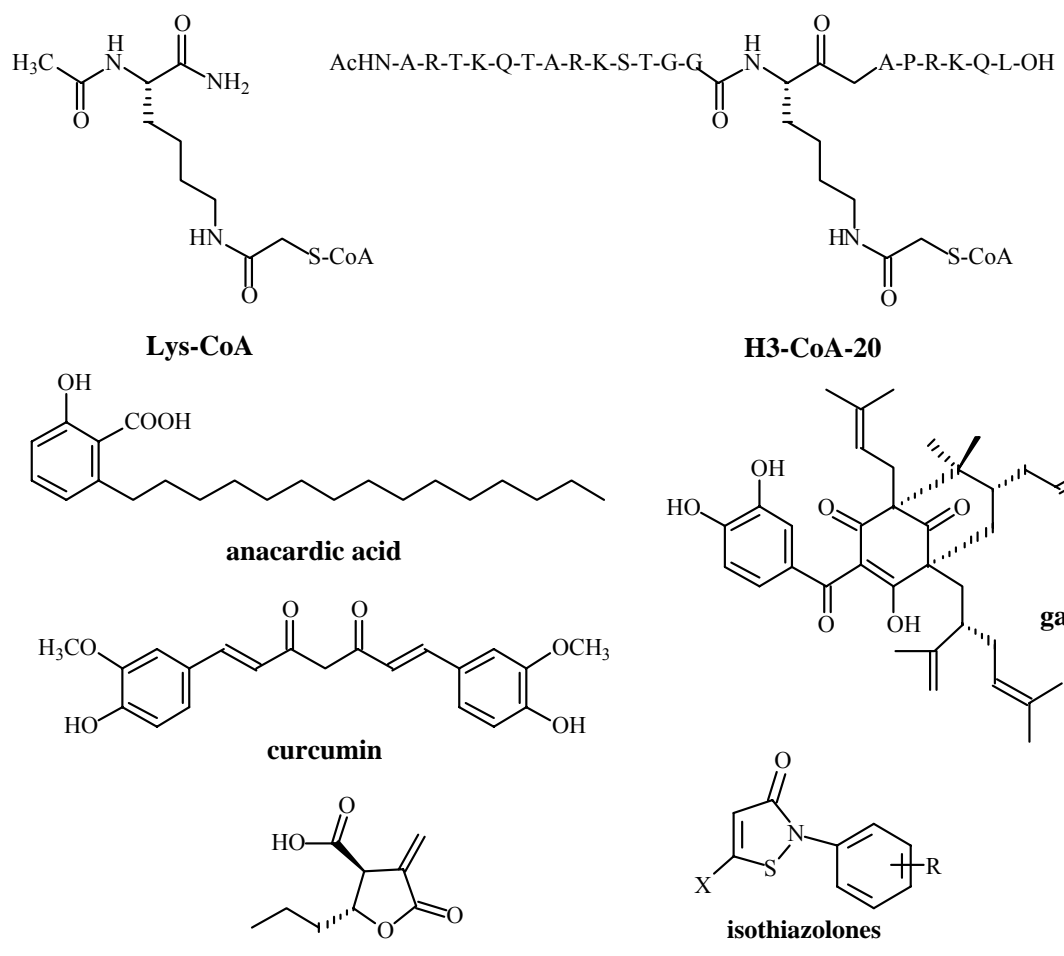

H3-CoA-20

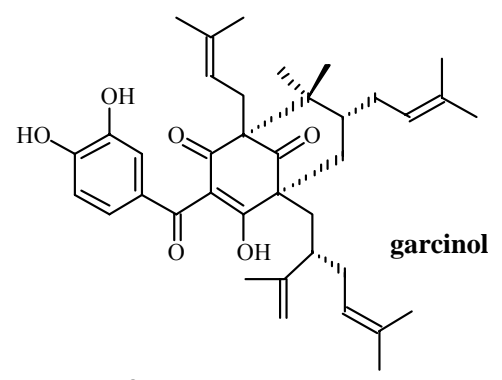

MB-3

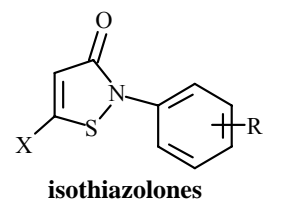

$\mathrm{X}=\mathrm{H}, \mathrm{Cl} ; \mathrm{R}=\mathrm{NO}_{2}, \mathrm{Cl}, \mathrm{CF}_{3}, \mathrm{OMe}, \mathrm{COOEt}$

Figure 1. Known HAT inhibitors.

Pursuing our searches on design, synthesis, and biological evaluation of small molecules as epigenetic tools for regulating gene expression and transcription, ${ }^{30-40}$ we performed a yeast phenotypic screening on a set of both newly synthesized and commercially available molecules (1-14) (Figure 2), to find among them one or more modulators of HAT activity. Between tested compounds, derivatives 1-4 were chosen because they resemble some structural similarities with the $\varepsilon$-acetyl-lysine, the product of acetylation reaction. 

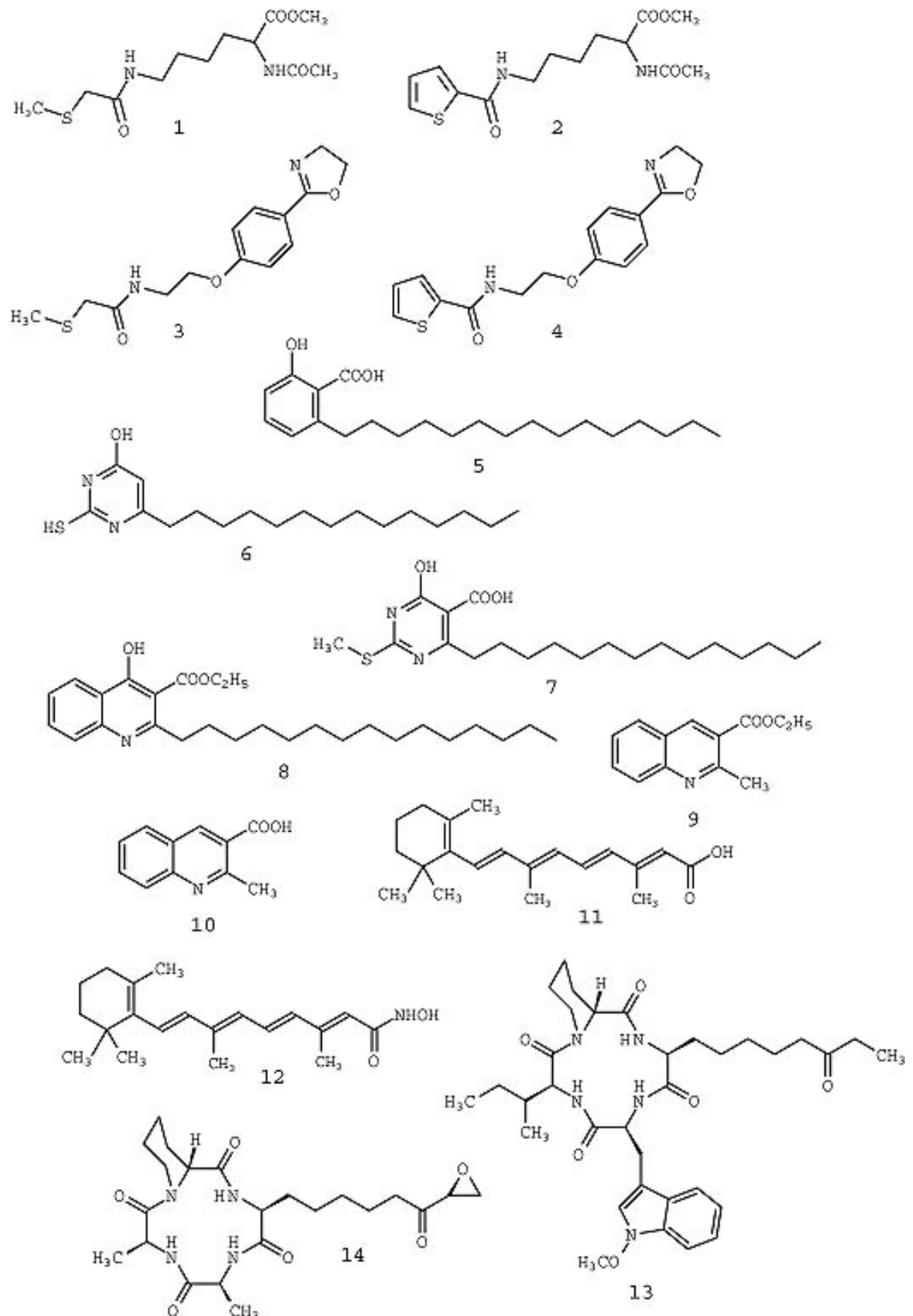

Figure 2. Compounds 1-14 subjected to the first phenotypic screening.

Anacardic acid (AA) 5, ${ }^{25}$ was used as the template for design and synthesis of several analogues 6-10, in which the AA benzene ring was replaced by pyrimidine $(6,7)$ or quinoline $(8)$ moiety, including the two simpler quinolines 9 and 10. All-trans retinoic acid (ATRA) 11, ${ }^{41}$ a well known transcriptional modulator, and the corresponding hydroxamate $\mathbf{1 2}$ also show some structural analogies with AA, and were included in the assay. Apicidin 13, ${ }^{42}$ and HC-Toxin 14, ${ }^{43}$ 
were two HDACi belonging to the cyclic tetrapeptide family, and were comprised in the cellbased test to study an eventual positive modulation of GCN5. Indeed, a amide analogue of AA ( $N$-(4-chloro-3-trifluoromethylphenyl)-2-ethoxy-6-pentadecylbenzamide, CTPB $)^{25}$ has been reported to be a p300 activator, and we expected that HDACi could show in cell-based assay a phenotype similar to that of HAT activators.

Between tested compounds 1-14, only the 3-carbethoxy-2-methylquinoline 9 was found active in inhibiting yeast cell growth. In Saccharomyces cerevisiae we have assessed that the $\mathbf{9}$ inhibitory effect is equivalent to a GCN5 loss-of-function mutation. ${ }^{44}$ From these results, a series of analogues of 9 (compounds 15-21) (Figure 3) were prepared and tested as GCN5 inhibitors.<smiles>CCOC(=O)c1c(C)nc2ccccc2c1O</smiles>

15<smiles>CCOC(=O)c1cccnc1C</smiles>

16<smiles>Cc1ccc2ccccc2n1</smiles>

17

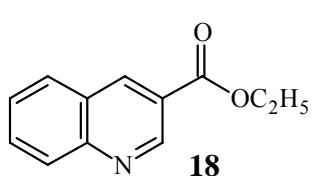<smiles>NC(=O)c1cnc2ccccc2c1</smiles>

Figure 3. Compounds 15-21 as analogues of 9 prepared for the second cell-based screening.

\section{Chemistry}

The $\varepsilon$-acetyl-lysine-based compounds 1 and 2 were prepared by acylation of $N \alpha$-acetyl-L-lysine methyl ester hydrochloride with methylthioacetic acid or thiophene-2-carboxylic acid in the presence of $N, N^{\prime}$-carbonyldiimidazole (Scheme 1). For the synthesis of $\mathbf{3}$ and $\mathbf{4}$, the same acylation reactions were performed on the 2-[4-(4,5-dihydrooxazol-2-yl)-phenoxy]ethylamine 22, prepared by Mitsunobu reaction between 2-aminoethanol and 4-(4,5-dihydrooxazol-2-yl)phenol 23, ${ }^{45}$ in the presence of (a) di-tert-butyl dicarbonate and (b) diisopropyl azodicarboxylate (DIAD)/triphenylphosphine followed by acidic removal of the protecting tert-butoxycarbonyl group (Scheme 1).

Acylation of potassium ethyl malonate with pentadecyl imidazolide in the presence of magnesium dichloride and triethylamine furnished the corresponding $\beta$-oxoester 24, which was in turn condensed with thiourea and sodium ethoxide in ethanol to give the 2-thiouracil 6. Following treatments of $\mathbf{6}$ with (a) methyl iodide, and (b) $N$-bromosuccinimide (NBS) afforded the 5-bromopyrimidine 25, that was converted into the 4-hydroxy-2-methylthio-6tetradecylpyrimidine-5-carboxylic acid 7 by reaction with $n$-butyl lithium and carbon dioxide at $78{ }^{\circ} \mathrm{C}$ (Scheme 2).

The 4-hydroxyquinolines 8 and 15 were obtained by reaction of ethyl 3-oxooctadecanoate (for 8) or ethyl acetoacetate (for 15) with isatoic anhydride in the presence of sodium hydroxide as catalyst (Scheme 3). The synthesis of $\mathbf{9}$ was accomplished by a single-step variant of the 
Friedländer synthesis involving $o$-nitrobenzaldehyde and ethyl acetoacetate in the presence of $\mathrm{SnCl}_{2}$ and $\mathrm{ZnCl}_{2}{ }^{44}$ and the corresponding carboxylic acid $\mathbf{1 0}{ }^{46}$ was obtained from $\mathbf{9}$ by standard procedure (Scheme 3).

The $N$-hydroxyretinamide $12^{47}$ was prepared by reaction of the commercial all-trans-retinoic acid 11 with ethyl chloroformate, followed by addition of $O$-(2-methoxy-2propyl)hydroxylamine, ${ }^{48}$ and subsequent acidic treatment in the presence of the Amberlyst ${ }^{\circledR} 15$ ion-exchange resin (Scheme 4).

The commercial 3-quinolinecarboxylic acid 20 was the starting material for the preparation of both the corresponding ethyl ester 18 (by standard method) ${ }^{49}$ and the carboxyamide $21,{ }^{50}$ (by two-step, one-pot reaction with ethyl chloroformate/2.5 $\mathrm{M}$ ammonia solution in dioxane). Finally, the ethyl 2-naphthoate 19 was prepared from 2-naphthoyl chloride by standard reaction. $^{51}$
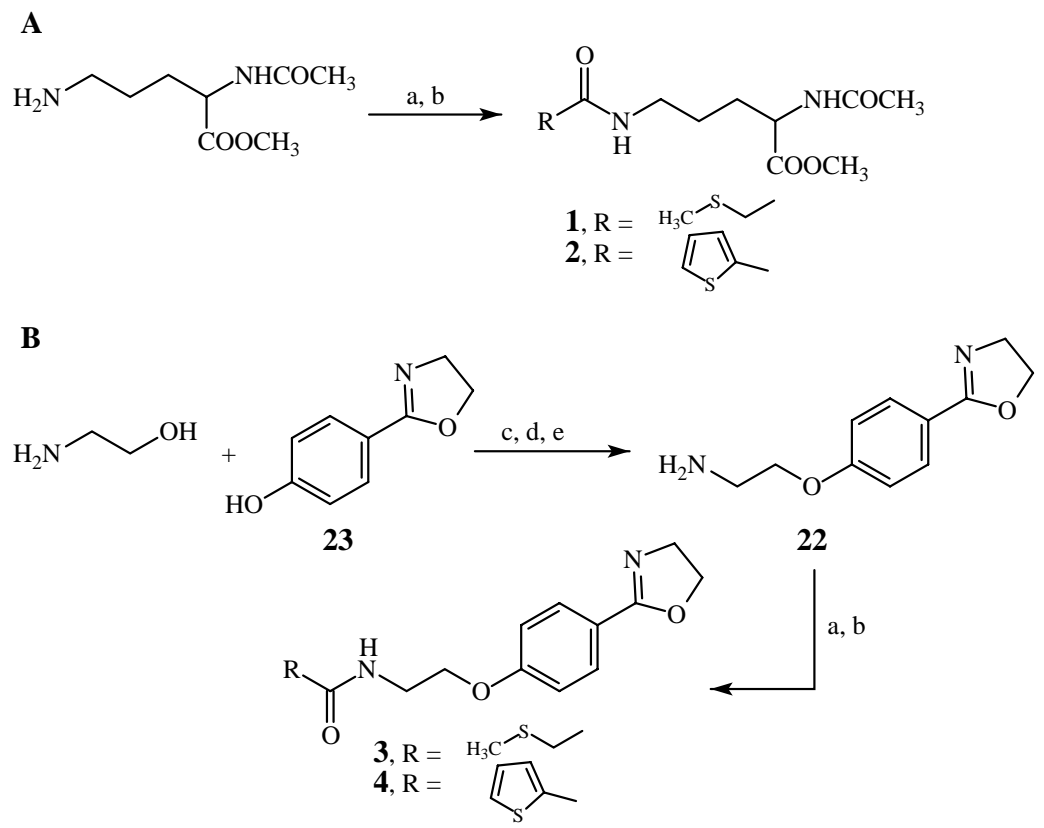

Reagents: (a): 2-methylmercaptoacetic acid or 2-thiophenecarboxylic acid; (b): $N, N^{\prime}$-carbonyldiimidazole; (c): ditert-butyl dicarbonate; (d): DIAD/PPh $;$; (e): $\mathrm{H}^{+}$.

Scheme 1. Synthesis of compounds 1-4. 


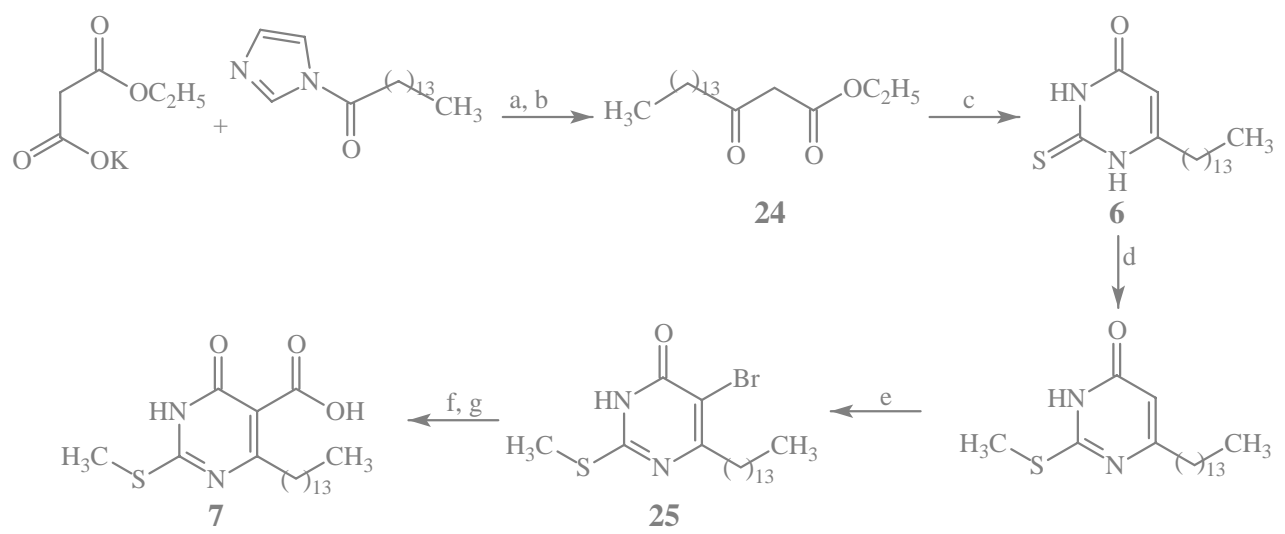

Reagents: (a): $\mathrm{MgCl}_{2}, \mathrm{Et}_{3} \mathrm{~N}$; (b): $\mathrm{H}^{+}$; (c): thiourea, EtONa; (d): MeI; (e): NBS; (f): $n$-butyl lithium; (g): $\mathrm{CO}_{2}$.

Scheme 2. Synthesis of compounds 6 and 7.

A

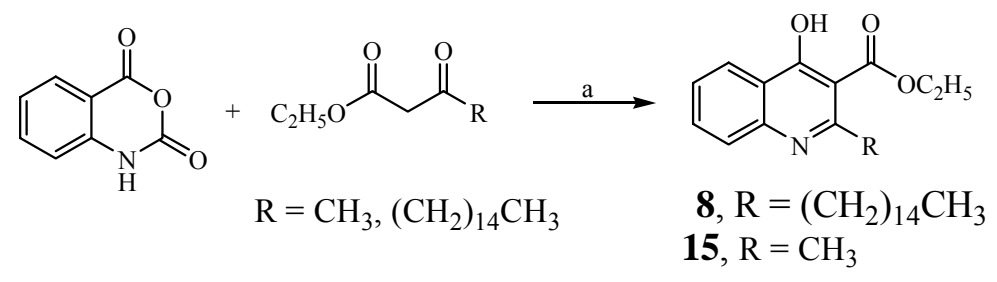

B

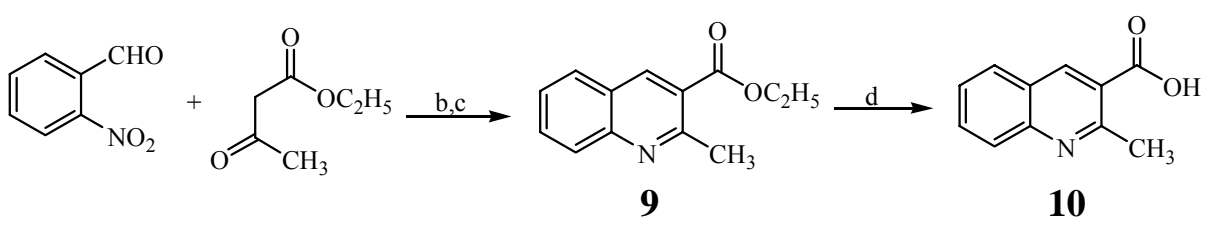

Reagents: (a): $\mathrm{NaOH}$; (b): $\mathrm{SnCl}_{2}$; (c): $\mathrm{ZnCl}_{2}$; (d): $\mathrm{KOH}$.

Scheme 3. Synthesis of compounds 8-10, 15. 


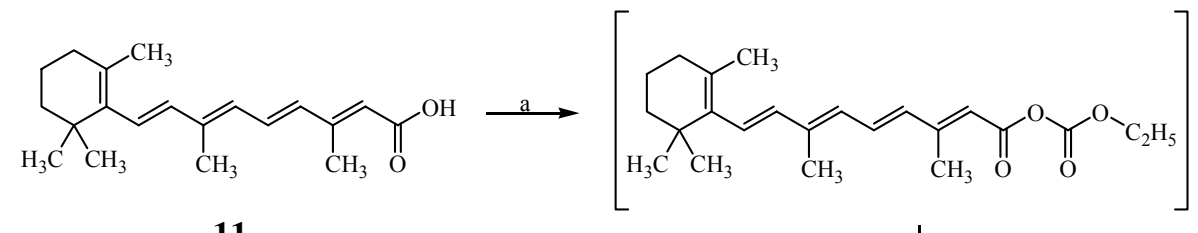

11

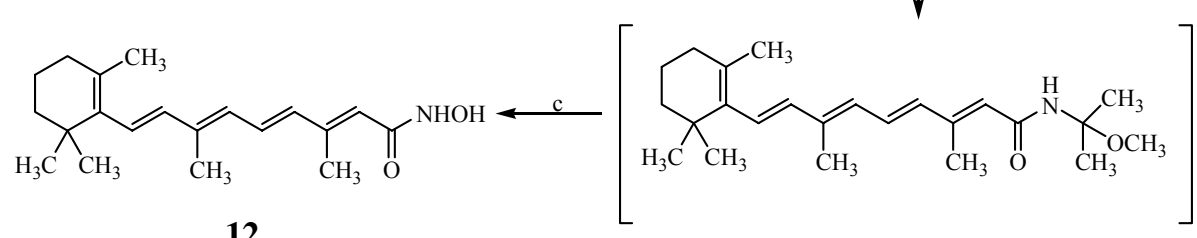

12

Reagents: (a): ClCOOEt, $\mathrm{Et}_{3} \mathrm{~N}$; (b): $\mathrm{H}_{2} \mathrm{NOC}\left(\mathrm{CH}_{3}\right)_{2} \mathrm{OCH}_{3}$; (c): $\mathrm{H}^{+}$.

Scheme 4. Synthesis of 12.

\section{Results and Discussion}

Compounds 1-14 were tested to evaluate the effect of growth inhibition of yeast cells. Because

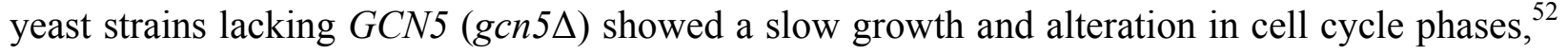
we expected that compounds slowing down the yeast cell growth could mimic the effects produced by the deletion of GCN5. Among the tested compounds 1-14 (Figure 4), only 9 gave a significant slow of cell growth at 0.2 to $1 \mathrm{mM}$ concentration. Tested on $g c n 5 \Delta$ yeast strain, 9 had just little effect of cell growth (Figure 5, left panel). To determine if there was a direct link between 9 activity and the HAT catalytic activity of GCN5, we tested the effect of 9 on growth in the mutant F221A yeast strain, that contains the F221A point mutation in the HAT minimal catalytic domain of yGCN5. Compared with the effect of 9 on the respective isogenic wild-type strain yMK839, the reduction of F221A growth was significantly lower (about 25\%) than that observed with MK839 (about 50\%) (Figure 5, right panel), thus providing the evidence that the 9 inhibition is exerted on the catalytic activity of GCN5 but not on the whole protein. 


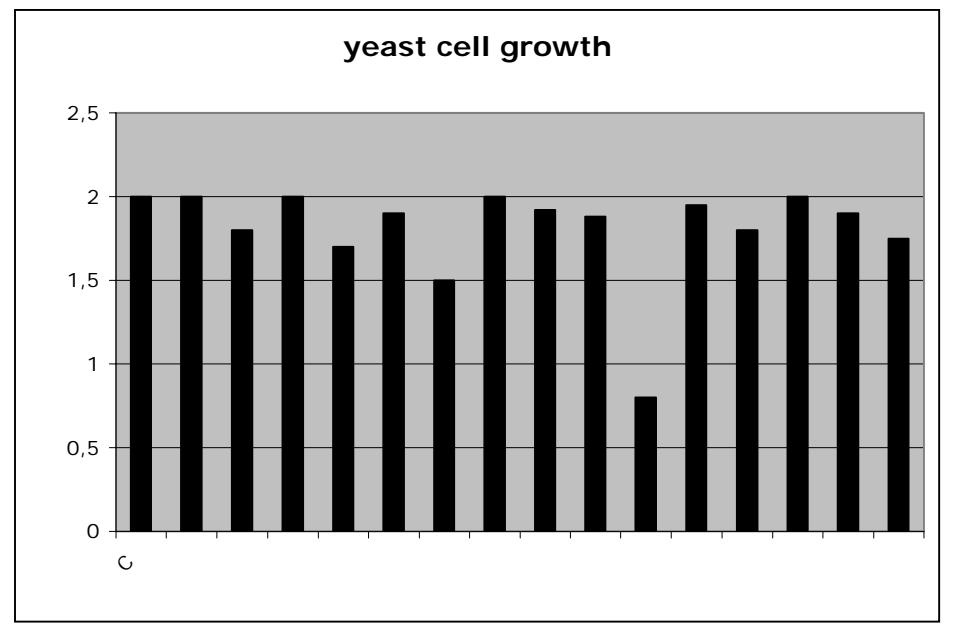

Figure 4. Inhibiting effect of 1-14 on yeast cell growth. The numbers of yeast cells were evaluated as arbitrary units by optical density.
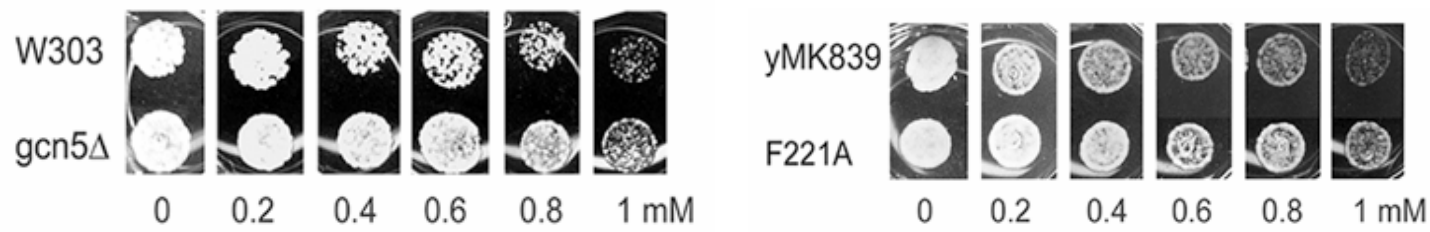

Figure 5. Inhibition of yeast cell growth in the presence of 0.2 to $1 \mathrm{mM}$ concentrations of 9 in wt (W303 and MK839), gcn5s, and F221A mutant strains.

Furthermore, we demostrated that the action of $\mathbf{9}$ on wild-type Saccharomyces cerevisiae is equivalent to a GCN5 loss-of-function mutation. The HAT activity of GCN5 is required for transcriptional activation of target genes in vivo. ${ }^{52}$ In yeast, GCN5 was first described as a transcriptional coactivator of amino acid biosynthetic genes, HIS3 being one of the most affected. Tested on HIS3-lacZ, GCN5-dependent activated transcription in wt strain under basal (SD medium) and activated (SD + 3-aminotriazole (3AT)) conditions, 9 strongly inhibited the yeast $\beta$-galactosidase activity, while failed in inhibiting the GCN5-undependent GAL10-CYC1lacZ transcription (Figure 6). 

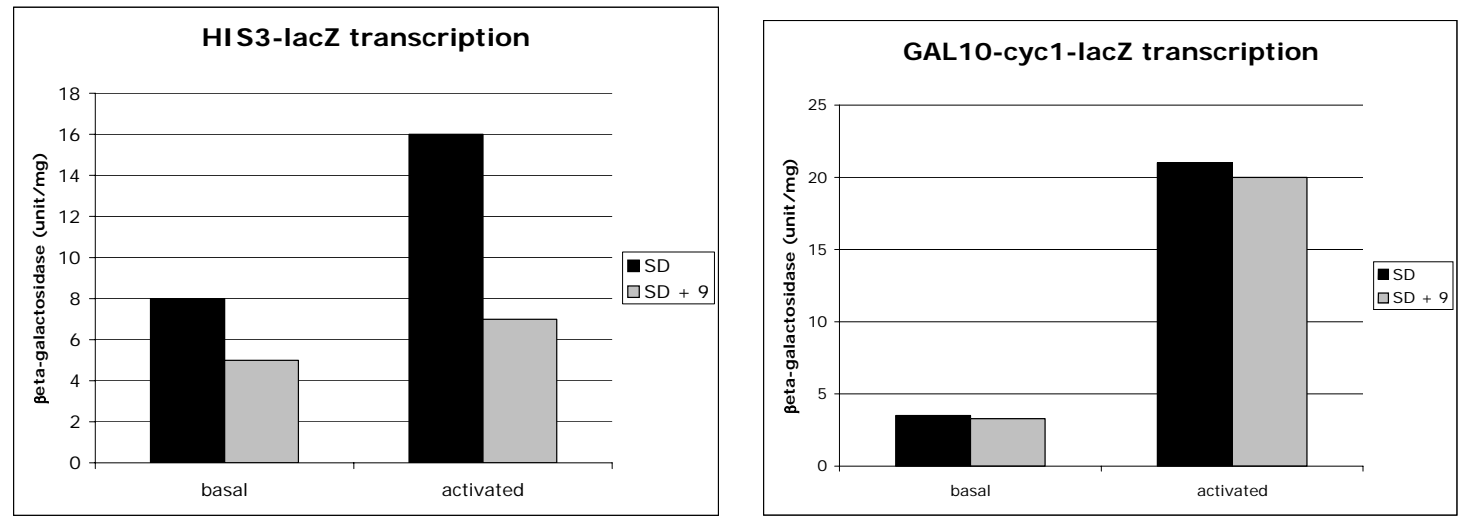

Figure 6. Effects of 9 on GCN5-dependent (left panel) and GCN5-undependent (right panel) transcription. Data represent mean values of at least three separate experiments.

To ascertain that acetylation reaction is the primary target for the inhibiting activity of $\mathbf{9}$, a in vivo assay was performed by measuring the acetylation level of histones $\mathrm{H} 3$ and $\mathrm{H} 4 \mathrm{~N}$-terminal tails in protein extracts from wt (W303) and gcn5s (yPO4) cells, grown for $16 \mathrm{~h}$ in YPD medium alone and in the presence of $0.6 \mathrm{mM}$ 9. In these conditions, 9 clearly inhibited $\mathrm{H} 3$ and, to a lesser extent, H4 histone tail acetylation (Figure 7).

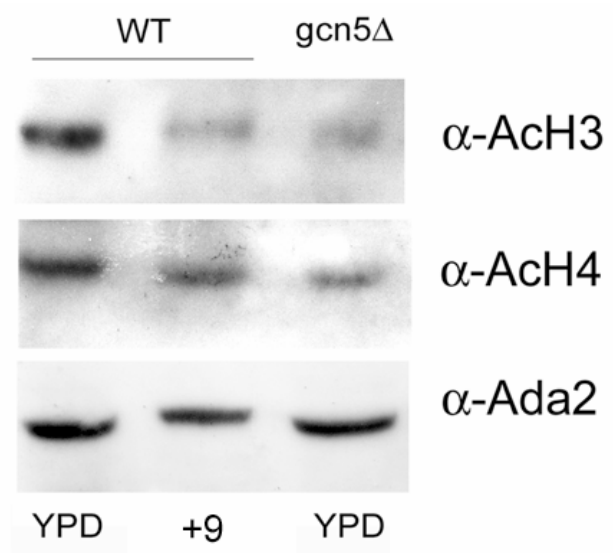

Figure 7. Effect of 9 on acetylation levels of yeast histones $\mathrm{H} 3$ and $\mathrm{H} 4$.

Prompted by these results, we prepared and tested in our cell-based phenotypic screen seven novel analogues of 9 (compounds 15-21), to acquire SAR information about the inhibiting activity. Among 15-21, only the 3-carbethoxyquinoline 18 was able to inhibit the growth of yW303 cells, it being less effective in inhibiting the gcn5s strain cell growth. The insertion of a hydroxyl group at the $\mathrm{C} 4$ position of 9 (compound 15) as well as the replacement of the quinoline of 9 with the pyridine (compound 16) or the deletion of the C3-carbethoxy function (compound 17) abolished the GCN5 inhibiting activity. Differently, compound 18 lacking the 
C2-methyl substituent retained the GCN5 inhibitory activity, but the replacement of its quinoline with naphthalene (19), or the introduction of a carboxyl (20) or carboxamide (21) function at the quinoline C3-position instead of the 3-carbethoxy moiety gave inactive products (Figure 8).

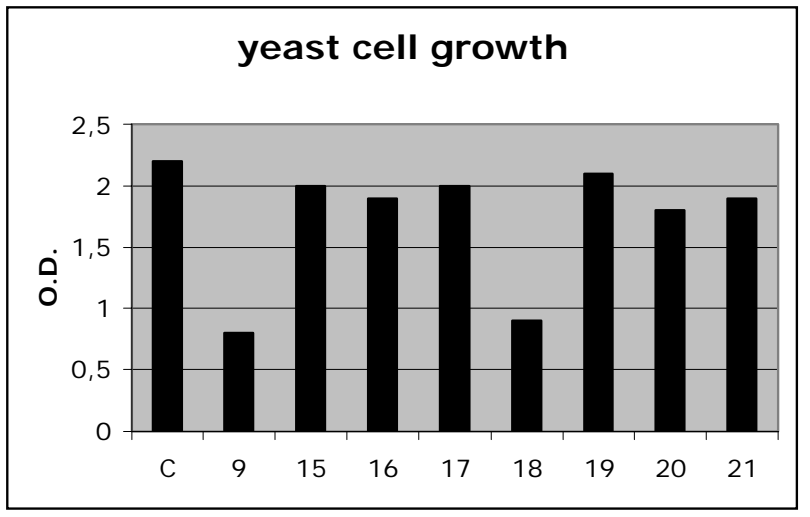

Figure 8. Yeast cell growth observed with compounds 15-21.

The 3-carbethoxyquinoline 18 and the 3-carbethoxy-2-methylpyridine 16 (as negative control) were tested in HIS3-lacZ transcription assay, to evaluate the functional inhibition of GCN5-dependent gene transcription. In this test, the reporter activity was highly reduced in the presence of 18 both in basal (SD medium) and, more drastically, in activated (SD +3AT) conditions, while the treatment with 16 was ineffective (Figure 9).

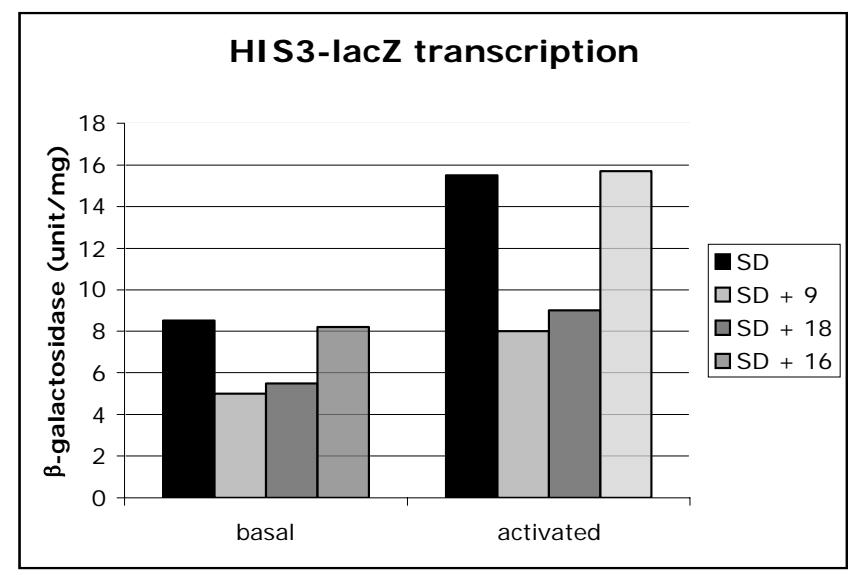

Figure 9. Effects of $\mathbf{1 8}$ and $\mathbf{1 6}$ on GCN5-dependent transcription. Data represent mean values of at least three separate experiments.

To investigate on human cell activities of 9 and 18, the effect on apoptosis induction in human leukemia U937 cell lines wase determined. After $24 \mathrm{~h}$, at $1 \mathrm{mM}$ concentration 9 was able to induce $27 \%$ of apoptosis, while 18 had just little effect in the same conditions (Figure 10). The 
two compounds also showed different capabilities in cell cycle arrest, compound 9 being the strongest (data not shown). Further studies on $\mathbf{9}$ and $\mathbf{1 8}$ will be performed in human cancer cell lines to deepen their effects on GCN5-related phenomena.

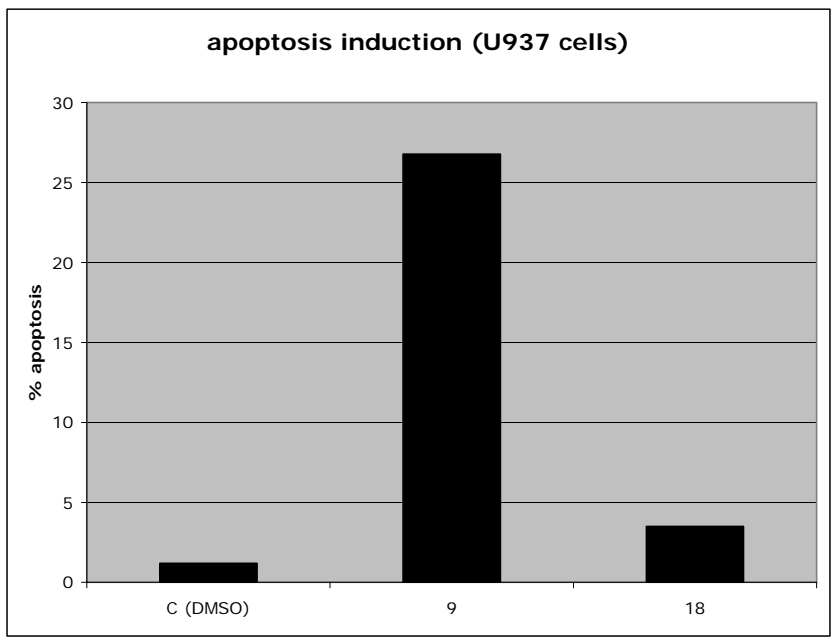

Figure 10. Apoptosis induction by 9 and 18 in human leukemia U937 cells. Data represent mean values of at least three separate experiments.

\section{Acknowledgements}

This work was partially supported by grants from AIRC 2005 (AM), PRIN 2004 (AM), PRIN 2004055579_03 (LA), and EU contract EPITRON n 518417 (LA).

\section{References}

1. Davie, J. R. Curr. Opin. Genet. Dev. 1998, 8, 173.

2. Kouzarides, T. Curr. Opin. Genet. Dev. 1999, 9, 40.

3. Strahl, B. D.; Allis, C. D. Nature 2000, 403, 41.

4. Pazin, M. J.; Kadonaga, J. T. Cell 1997, 89, 325.

5. Glass, C. K.; Rosenfeld, M. G. Genes Dev. 2000, 14, 121.

6. Luger, K.; Mader, A. W.; Richmond, R. K.; Sargent, D. F.; Richmond, T. J. Nature 1998, 389, 251.

7. Urnov, F. D.; Wolffe, A. Emerg. Ther. Targets 2000, 4, 665.

8. Fischle, W.; Wang, Y.; Allis, C. D. Curr. Opin. Cell Biol. 2003, 15, 172.

9. Akey, C. W.; Luger, K. Curr. Opin. Struc. Biol. 2003, 13, 6.

10. Roth, S. Y.; Denu, J. M.; Allis, C. D. Annu. Rev. Biochem. 2001, 70, 81. 
11. Sterner, D. E.; Berger, S. L. Microbiol. Mol. Biol. Rev. 2000, 64, 435.

12. Marmorstein, R. J. Mol. Biol. 2001, 311, 433.

13. Schiltz, R. L.; Mizzen, C. A.; Vassilev, A.; Cook, R. G.; Allis, C. D.; Nakatani, Y. J. Biol. Chem. 1999, 274, 1189.

14. Lau, O. D.; Courtney, A. D.; Vassilev, A.; Marzilli, L. A.; Cotter, R. J.; Nakatani, Y.; Cole, P. A. J. Biol. Chem. 2000, 275, 21953.

15. Grant, P. A., Duggan, L.; Cote, J.; Roberts, S. M.; Brownell, J. E.; Candau, R.; Ohba, R.; Owen-Hughes, t.; Allis, C. D.; Winston, F.; Berger, S. L.; Workman, J. L. Genes Dev. 1997, 11,1640 .

16. Grant, P. A.; Eberharter, A.; John, S.; Cook, R. G.; Turner, B. M.; Workman, J. L. J. Biol. Chem. 1999, 274, 5895.

17. Mai, A.; Massa, S.; Rotili, D.; Cerbara, I.; Valente, S.; Pezzi, R.; Simeoni, S.; Ragno, R. Med. Res. Rev. 2005, 25, 261.

18. Minucci, S.; Pelicci, P. G. Nat. Rev. Cancer 2006, 6, 38.

19. Muraoka, M.; Konishi, M.; KiKuchi-Yanoshita, R.; Tanaka, K.; Shitara, N.; Chong, J. M.; Iwama, T.; Miyaki, M. Oncogene 1996, 12, 1565.

20. Sakakura, C.; Hagiwara, A.; Yasuoka, R.; Fujita, Y.; Nakanishi, M.; Masuda, K.; Kimura, A.; Nakamura, Y.; Inazawa, J.; Abe, T.; Yamagishi, H. Int. J. Cancer 2000, 89, 217.

21. Puri, P. L., Sartorelli, V.; Yang, X. J.; Hamamori, Y.; Ogryzko, V. V.; Howard, B. H.; Kedes, L.; Wang, J. Y.; Graessmann, A.; Nakatani, Y.; Levrero, M. Mol. Cell 1997, 1, 35.

22. Lehrmann, H.; Pritchard, L. L.; Harel-Bellan, A. Adv. Cancer Res. 2002, 86, 41.

23. Zheng, Y.; Thompson, P. R.; Cebrat, M.; Wang, L.; Devlin, M. K.; Alani, R. M.; Cole, P. A. Methods Enzymol. 2004, 376, 188.

24. Lau, O. D.; Kundu, T. K.; Soccio, R. E.; Ait-Si-Ali, S.; Khalil, E. M.; Vassilev, A.; Wolffe, A. P.; Nakatani, Y.; Roeder, R. G.; Cole, P. A. Mol. Cell 2000, 5, 589.

25. Balasubramanyam, K.; Swaminathan, V.; Ranganathan, A.; Kundu, T. K. J. Biol. Chem. 2003, 278, 19134.

26. Balasubramanyam, K.; Altaf, M.; Varier, R. A.; Swaminathan, V.; Ravindran, A.; Sadhale, P. P.; Kundu, T. K. J. Biol. Chem. 2004, 77, 33716.

27. Balasubramanyam, K.; Varier, R. A.; Altaf, M.; Swaminathan, V.; Siddappa, N. B.; Ranga, U.; Kundu, T. K. J. Biol. Chem. 2004, 279, 51163.

28. Biel, M.; Kretsovali, A.; Karatzali, E.; Papamatheakis, J., Giannis, A. Angew. Chem. Int. Ed. 2004, 43, 3974.

29. Stimson, L.; Rowlands, M. G.; Newbatt, Y. M.; Smith, N. F.; Raynaud, F. I.; Rogers, P.; Bavetsias, V.; Gorsuch, S.; Jarman, M.; Bannister, A.; Kouzarides, T.; McDonald, E.; Workman, P.; Aherne, G. W. Mol. Cancer Ther. 2005, 4, 1521.

30. Massa, S.; Mai, A.; Sbardella, G.; Esposito, M.; Ragno, R.; Loidl, P.; Brosch, G. J. Med. Chem. 2001, 44, 2069.

31. Mai, A.; Massa, S.; Ragno, R.; Esposito, M.; Sbardella, G.; Nocca, G.; Scatena, R.; Jesacher, F.; Loidl, P.; Brosch, G. J. Med. Chem. 2002, 45, 1778. 
32. Mai, A.; Massa, S.; Ragno, R.; Cerbara, I.; Jesacher, F.; Loidl, P.; Brosch, G. J. Med. Chem. 2003, 46, 512.

33. Mai, A.; Massa, S.; Pezzi, R.; Rotili, D.; Loidl, P.; Brosch, G. J. Med. Chem. 2003, 46, 4826.

34. Mai, A.; Massa, S.; Cerbara, I.; Valente, S.; Ragno, R.; Bottoni, P.; Scatena, R.; Loidl, P.; Brosch, G. J. Med. Chem. 2004, 47, 1098.

35. Ragno, R.; Mai, A.; Massa, S.; Cerbara, I.; Valente, S.; Bottoni, P.; Scatena, R.; Jesacher, F.; Loidl, P.; Brosch, G. J. Med. Chem. 2004, 47, 1351.

36. Mai, A.; Massa, S.; Pezzi, R.; Simeoni, S.; Rotili, D.; Nebbioso, A.; Scognamiglio, A.; Altucci, L.; Loidl, P.; Brosch, G. J. Med. Chem. 2005, 48, 3344.

37. Mai, A.; Massa, S.; Lavu, S.; Pezzi, R.; Simeoni, S.; Ragno, R.; Mariotti, F. R.; Chiani, F.; Camilloni, G.; Sinclair, D. A. J. Med. Chem. 2005, 48, 7789.

38. Mai, A.; Massa, S.; Rotili, D.; Pezzi, R.; Bottoni, P.; Scatena, R.; Meraner, J.; Brosch, G. Bioorg. Med. Chem. Lett. 2005, 15, 4656.

39. Mai, A.; Massa, S.; Pezzi, R.; Valente, S.; Loidl, P.; Brosch, G. Medicinal Chemistry 2005, $1,245$.

40. Mai, A.; Massa, S.; Valente, S.; Simeoni, S.; Ragno, R.; Bottoni, P.; Scatena, R.; Brosch, G. ChemMedChem 2006, 1, 225.

41. Warrell, R. P., Jr; Frankel, S. R.; Miller, W. H., Jr; Scheinberg, D. A.; Itri, L. M.; Hittelman, W. N.; Vyas, R.; Andreeff, M.; Tafuri, A.; Jakubowski, A. N. Engl. J. Med. 1991, 324, 1385.

42. Han, J.W.; Ahn, S.H.; Park, S.H.; Wang, S.Y.; Bae, G.U.; Seo, D.W.; Known, H.K.; Hong, S.; Lee, Y.W.; Lee, H.W. Cancer Res. 2000, 60, 6068.

43. Shute, R.E.; Dunlap, B.; Rich, D.H. J. Med. Chem. 1987, 30, 71.

44. Ornaghi, P.; Rotili, D.; Sbardella, G.; Mai, A.; Filetici, P. Biochem. Pharmacol. 2005, 70, 911.

45. Diana, G. D.; McKinlay, M. A.; Otto, M. J.; Akullian, V.; Oglesby, C. J. Med. Chem. 1985, 28, 1906.

46. Ladner, D. W. Synthetic Commun. 1986, 16, 157.

47. Ech-Chahad, A.; Minassi, A.; Berton, L.; Appendino, G. Tetrahedron Lett. 2005, 46, 5113.

48. Mori, K.; Koseki, K. Tetrahedron 1988, 44, 6013.

49. Nyoung Kim, J.; Mi Chung, Y.; Jin Im, Y. Tetrahedron Lett. 2002, 43, 6209.

50. Ma, Z.; Hano, Y.; Nomura, T.; Chen, Y. Bioorg. Med. Chem. Lett. 2004, 14, 1193.

51. Asao, N.; Nogami, T.; Lee, S.; Yamamoto, Y. J. Amer. Chem. Soc. 2003, 125, 10921.

52. Howe, L. A.; Auston, D.; Grant, P.; John, S.; Cook, R. G.; Workman, J. L.; Pillus, L. Genes Dev. 2001, 15, 3144. 